\title{
Ants Co-Occurring with Predatory Antlions Show Unsuccessful Rescue Behavior towards Captured Nestmates
}

\author{
Filip Turza • Gabriela Zuber • Michał Bzoma • \\ Monika Prus • Michał Filipiak • Krzysztof Miler
}

Received: 12 October 2019/Revised: 16 December 2019/Accepted: 31 January 2020 /Published online: 5 February 2020

(C) The Author(s) 2020

\begin{abstract}
The interaction of antlions and ants is postulated to be a predator-prey interaction in which the involved parties coevolve. Here, we investigated two issues of potential significance in terms of antlions and ants imposing selective pressures on one another. First, we determined whether trap-building antlions and sanddwelling ants closely co-occurred in an area inhabited by both. In the field, we found that ants were the main potential prey items in artificial traps placed inside aggregation zones of antlions and that Formica cinerea workers comprised the majority of these ants. Second, we checked whether rescue behavior, a type of prosocial behavior displayed by $F$. cinerea workers and performed towards nestmates captured by antlions, reduced the hunting success of the latter. In the laboratory, we found that rescue attempts were very rarely successful. Overall, caution must be used when considering the coevolution of antlions and ants. Clearly, even though these two organisms can closely co-occur, the rescue behavior of ants seems to be unrelated to the predatory threat from antlions.
\end{abstract}

Keywords Antlions · Ants - Euroleon - Formica . Myrmeleon $\cdot$ Predator-prey interaction

\footnotetext{
F. Turza · G. Zuber · M. Bzoma - M. Prus · M. Filipiak Institute of Environmental Sciences, Faculty of Biology, Jagiellonian University, Gronostajowa 7, 30-387 Kraków, Poland

K. Miler $(\bowtie)$

Institute of Systematics and Evolution of Animals, Polish Academy of Sciences, Sławkowska 17, 31-016 Kraków, Poland e-mail: miler@isez.pan.krakow.pl
}

\section{Introduction}

Predator-prey interactions are considered to be among the main reasons for coevolution, i.e., a phenomenon in which organisms exert selective pressures on one another (Janzen 1980). Indeed, from the perspective of the prey community, it is important to develop and improve the abilities to survive and increase fitness (Moore and Biewener 2015). Avoiding death by predation can be accomplished in various ways, sometimes quite spectacularly. For example, a moth prey of the genus Bertholdia broadened its defensive repertoire over the course of evolution by developing ultrasonic clicks that jam sonars used by their bat predators in the genus Eptesicus (Corcoran et al. 2009).

Some antlions (Neuroptera: Myrmeleontidae) are "sit and wait" predators (Perry and Pianka 1997) with larvae that use traps while feeding under natural conditions. Trap building has evolved rarely in the animal kingdom (Ruxton and Hansell 2009). The uniqueness of this foraging strategy has long attracted attention to antlions, which possess several traits that make them seemingly efficient predators (Miler et al. 2017a). These traits include strong mandibles used for injecting paralytics (Matsuda et al. 1995; Nishiwaki et al. 2007), high vibration sensitivity that helps them detect approaching prey (Devetak et al. 2007; Fertin and Casas 2007) and learning abilities that allow them to improve foraging strategies (Kuszewska et al. 2016; Miler et al. 2017b). However, the diet of antlions is not well known, mostly mentioned anecdotally in studies on other questions (Heinrich and Heinrich 1984; Matsura 1986, 1987; 
Cain 1987; Gotelli 1996; Morrison 2004; Barkae et al. 2017; Jingu and Hayashi 2018). Sand-dwelling ants are most often indicated as the prey of antlions, and circumstantial evidence suggests that antlion threats towards these ants are strong and result in selection pressures towards the evolution of their various defense strategies. For instance, it has been shown that these ants have means of securing their immediate release when caught by antlion larvae (Lucas and Brockmann 1981; Eisner et al. 1993) and that they may show rescue behavior towards nestmates caught by antlion larvae (Czechowski et al. 2002; Hollis and Nowbahari 2013; Miler et al. 2017c). All of these findings have led to claims of coevolution between antlions and ants (Hollis et al. 2015; Hollis 2017).

Here, we investigated two issues of potential significance in terms of antlions and ants imposing selective pressures on one another. Addressing the diet of antlions, we first aimed to determine the potential prey of two species of antlions, Myrmeleon bore and Euroleon nostras. Using artificial traps placed inside aggregation zones of these antlions in the field, we determined whether antlions and ants closely co-occurred. We predicted that ants would comprise the majority of the potential prey and that Formica cinerea ants would be the main potential prey item, a species known to display rescue behavior (Miler 2016; Miler and Kuszewska 2017; Miler et al. 2017c, d). Thus, we also addressed the question of whether rescue attempts of F. cinerea workers decrease the hunting success of antlions. We predicted that rescue behavioral patterns would be successful and would increase the chances of captured individuals escaping predation. To verify this prediction, we performed rescue behavior tests in the laboratory.

\section{Methods}

The potential prey of larvae was assessed in the field near Klucze (southern Poland, Błędowska Desert). Błędowska Desert is inhabited by at least two species of antlions, $M$. bore and E. nostras, with former being abundant and occurring in open space exposed to direct sunlight, with only lower instars sometimes seeking protection from wind and rain under hanging branches, and the latter always occurring in isolated patches highly protected from wind, rain and direct sunlight. F. cinerea sand-dwelling ants are common throughout the area.
Cylindrical plastic vessels $(3 \mathrm{~cm}$ in diameter, $11 \mathrm{~cm}$ in length) were used as artificial traps, covered on the inside with Fluon (Sigma-Aldrich, Germany). These vessels were put in the sand, 5 within the $M$. bore antlion zone and 5 within the E. nostras antlion zone, collected once per week and replaced by fresh ones from May to September. The vessels were buried at $30 \mathrm{~cm}$ intervals and were not baited. Collected vessels were closed with a cap and dried, and then their contents were examined. If arthropods were present, they were identified to the family level. If identification was not possible, the arthropods were listed together as "unidentifiable". The data were pooled into four-week periods. For each period, the percentage of Formicidae among all identified potential prey was calculated separately for each species of antlion. Additionally, the percentage of $F$. cinerea individuals among Formicidae was calculated for each species of antlion.

Tests of rescue behavior were performed in the laboratory on animals collected in the field at the same location. We collected $50 \mathrm{M}$. bore and $50 \mathrm{E}$. nostras antlion larvae. Approximately $500 \mathrm{~F}$. cinerea foragers from each of two colonies were also collected. The taxonomic identity of animals was confirmed in the laboratory, following appropriate keys (Czechowski et al. 2012; Badano and Pantaleoni 2014). Ants were kept in two separate plastic boxes $(25 \times 17 \times 10 \mathrm{~cm}$ each), with walls covered with Fluon (Sigma-Aldrich, Germany), and food and water were provided ad libitum. All larvae were placed in paper test boxes (a separate box for each larva; $13 \times 13 \times 4.5 \mathrm{~cm}$ ) filled with dry, sieved, fine-grained sand collected from the original habitat. Each larva was placed in the middle of its box, and then a plastic ring $(7 \mathrm{~cm}$ in diameter) was placed on top of the sand to force the larva to build its trap within. This ring was removed after approximately $20 \mathrm{~h}$, and tests started shortly thereafter. For the tests, a plastic ring (10 $\mathrm{cm}$ in diameter) covered in Fluon (Sigma-Aldrich, Germany) was placed in the box with an antlion equipped with a functional trap. A group of six ants was introduced into the ring, on the flattened surface around the antlion trap. We noted for 3 min whether any of these ants were captured, and if so, then we prolonged the observational period for 3 min since capture. During that time, we noted whether any signs of rescue behavior occurred in any of the remaining ants ( $0 / 1$ response), measured the latency to the first episode of rescue (if one occurred), and whether rescue was successful. This type of testing can be considered ecologically relevant based 
on previous field observations (Czechowski et al. 2002). We used pulling at the limbs/antennae/mandibles of the captured individual, digging around it, removal of the sand covering it, and direct attack on the antlion mandibles as signs of rescue behavior (Miler 2016). For the antlions that captured prey, we compared the number of tests with rescue between the two antlion species using Fisher's exact test (FET) in STATISTICA 13 software (Tibco, USA). Then, the median latency to the first episode of rescue in all tests in which rescue occurred was calculated. Data were not further analyzed due to a lack of successful rescues (see below).

\section{Results}

Arthropods captured in artificial traps were identified to the family level (Table 1). During the entire period of the survey, Formicidae comprised a gross majority of the potential prey for $M$. bore $(\sim 98 \%)$. In the case of E. nostras, Formicidae comprised the majority in July and August ( 73-99\%) but not during the remaining months ( 29-50\%). Importantly, F. cinerea workers comprised approximately 99 and $97 \%$ of the total captured Formicidae in $M$. bore and E. nostras aggregation zones, respectively.

Among the $50 \mathrm{M}$. bore and $50 \mathrm{E}$. nostras antlion larvae collected, 47 of the former and 33 of the latter constructed functional traps under laboratory conditions. Only these individuals participated in rescue behavior tests. Ants were captured by either antlion species in the case of 48 tests in total. Rescue attempts occurred in 28 of these 48 tests (58\%), and there was no difference in the proportion of tests with rescue attempts between antlion species (16 of 28 in M. bore and 12 of 20 in E. nostras; FET yielded $p=1.000$ ). The first episodes of rescue behavior occurred after a median latency \pm SD of $42 \pm 31$ s. No rescue attempt was successful. In 3 tests, the captured individual was released dead, and another ant was captured in its place.

\section{Discussion}

We show here that ants, especially $F$. cinerea workers, were generally abundant in the artificial traps placed in the antlion-inhabited areas throughout the season. Interestingly, the largest numbers of these ants coincided with the highest point of their colony development
(Czechowski et al. 2002) as well as the highest ambient temperatures, favoring the physiological capacity of trap building in antlions (Antoł et al. 2018). Even if our data overestimated what antlions can truly catch as prey and only a subset of the potential prey presented herein were within their reach (Humeau et al. 2015), it is highly likely that ants are nevertheless the main prey of antlions, as is often assumed.

Earlier observations of Tetramorium ants facing unknown species of antlions indicated that these ants rarely rescue their nestmates successfully (Taylor et al. 2013). The present results also suggest that rescue behavior is without ecological relevance in the context of antlion larva capture. This conclusion is supported by a very narrow time frame available for rescue in this context. Antlions inject paralytics into their captured prey; these paralytics cause paralysis in ants at a maximum of $2 \mathrm{~min}$ after injection (Griffiths 1980; Matsuda et al. 1995; Nishiwaki et al. 2007). Taking into account the fact that the captured ant has to "call for help" to elicit rescue in its nestmates (Czechowski et al. 2002; Frank et al. 2017; Miler and Kuszewska 2017), these 2 min leave little room for a successful rescue action, which is expressed after a delay (here, median latency \pm SD: $42 \pm 31 \mathrm{~s}$ ). It seems plausible that rescue behavioral patterns in F. cinerea, and possibly other sand-dwelling ants, are more of an artefact in the context of antlion larva capture (stemming, e.g., from ants' inability to differentiate between entrapment contexts). It is worth noting that F. polyctena ants, forest groundcover species that never meet antlions in nature but probably face other entrapment situations, show rescue behaviors in an antlion larva capture context (Miler et al. 2017c), supporting the idea that ants do not differentiate between entrapment contexts. Nest cave-ins are likely much more important than antlion encounters for the evolution of rescue behavioral patterns in $F$. cinerea species, as well as in other sand-dwelling ants. Such a conclusion, however, would need additional support, preferably from studies conducted under field conditions. Such studies could additionally aim to estimate the predation rate of ants by antlions since, if low, this rate could provide another evidence that rescue attempts are artefacts in the context of antlion larva capture.

Naturally, the present results do not mean that sanddwelling ants are helpless in terms of antlion larva capture. Ants can minimize the risk of predation by avoiding antlion aggregation zones to some extent (Gotelli 1996; Morrison 2004; Hollis et al. 2017), which 
Table 1 The potential prey of $M$. bore and E. nostras throughout the season. Data show arthropods captured in artificial pits placed inside antlion zones of both antlion species. Unidentifiable specimens were degraded and mostly comprised of Diptera

\begin{tabular}{|c|c|c|c|c|}
\hline \multirow[t]{2}{*}{ Dates of collection (2018) } & \multicolumn{4}{|c|}{$\begin{array}{l}\text { Captured arthropods } \\
\text { (in count order) }\end{array}$} \\
\hline & in M. bore & & in E. nostras & \\
\hline & family & count & family & count \\
\hline \multirow[t]{8}{*}{$05.05-26.05$} & Formicidae & 326 & Formicidae & 6 \\
\hline & Carabidae & 3 & Curculionidae & 4 \\
\hline & Curculionidae & 3 & Carabidae & 3 \\
\hline & Acrididae & 1 & Staphylinidae & 3 \\
\hline & Cleridae & 1 & Myrmeleontidae & 2 \\
\hline & Elateridae & 1 & Nitidulidae & 2 \\
\hline & Unidentifiable & 1 & Scarabaeidae & 1 \\
\hline & & & Unidentifiable & 5 \\
\hline \multirow[t]{9}{*}{$02.06-23.06$} & Formicidae & 192 & Formicidae & 9 \\
\hline & Carabidae & 2 & Myrmeleontidae & 8 \\
\hline & Staphylinidae & 1 & Curculionidae & 6 \\
\hline & Unidentifiable & 2 & Aphididae & 2 \\
\hline & & & Oxyopidae & 2 \\
\hline & & & Crabronidae & 1 \\
\hline & & & Culicidae & 1 \\
\hline & & & Staphylinidae & 1 \\
\hline & & & Unidentifiable & 11 \\
\hline \multirow[t]{6}{*}{$30.06-21.07$} & Formicidae & 357 & Formicidae & 604 \\
\hline & Carabidae & 3 & Curculionidae & 5 \\
\hline & Staphylinidae & 2 & Myrmeleontidae & 2 \\
\hline & Acrididae & 1 & Cerambycidae & 1 \\
\hline & Stratiomyidae & 1 & Chrysomelidae & 1 \\
\hline & Unidentifiable & 14 & Unidentifiable & 3 \\
\hline \multirow[t]{10}{*}{$28.07-18.08$} & Formicidae & 472 & Formicidae & 36 \\
\hline & Byrrhidae & 3 & Myrmeleontidae & 2 \\
\hline & Carabidae & 3 & Curculionidae & 3 \\
\hline & Sphecidae & 2 & Carabidae & 2 \\
\hline & Chrysomelidae & 1 & Crabronidae & 2 \\
\hline & Curculionidae & 1 & Aradidae & 1 \\
\hline & Unidentifiable & 4 & Cerambycidae & 1 \\
\hline & & & Chrysomelidae & 1 \\
\hline & & & Vespidae & 1 \\
\hline & & & Unidentifiable & 1 \\
\hline \multirow[t]{5}{*}{$25.08-15.09$} & Formicidae & 89 & Formicidae & 6 \\
\hline & Carabidae & 2 & Myrmeleontidae & 4 \\
\hline & Geotrupidae & 1 & Carabidae & 1 \\
\hline & Unidentifiable & 3 & Throscidae & 1 \\
\hline & & & Unidentifiable & 1 \\
\hline
\end{tabular}


is their first "line of defense" against antlions. Additionally, earlier results obtained in rescue behavior investigations utilizing antlions (see, e.g., Miler 2016) are not invalidated by the present findings since rescue is a general behavioral category and major factors contributing to its occurrence (e.g., life expectancy) may very well be highly context independent.

In summary, it is tempting to look for evidence of coevolution between antlions and ants (Hollis et al. 2015; Hollis 2017). As we show here with $F$. cinerea workers, sand-dwelling ants may closely co-occur with trap-building antlions. However, it seems that the rescue actions of these ants are unlikely displayed as a countermeasure to strong selection pressure from antlions. The question of antlion and ant mutual dependence remains open, however, even in light of the present results. An important further step in investigating this issue would be to conduct a broader-scale study to analyze the geographical distribution of both taxa with a focus on their degree of overlap.

Acknowledgements The study was funded by the National Science Centre, Poland (grant PRELUDIUM no. 2018/31/N/NZ8/02312 awarded to FT). KM was supported by the Foundation for Polish Science under the START program.

Open Access This article is licensed under a Creative Commons Attribution 4.0 International License, which permits use, sharing, adaptation, distribution and reproduction in any medium or format, as long as you give appropriate credit to the original author(s) and the source, provide a link to the Creative Commons licence, and indicate if changes were made. The images or other third party material in this article are included in the article's Creative Commons licence, unless indicated otherwise in a credit line to the material. If material is not included in the article's Creative Commons licence and your intended use is not permitted by statutory regulation or exceeds the permitted use, you will need to obtain permission directly from the copyright holder. To view a copy of this licence, visit http://creativecommons.org/licenses/by/4.0/.

\section{References}

Antoł A, Rojek W, Miler K, Czarnoleski M (2018) Thermal dependence of trap building in predatory antlion larvae (Neuroptera: Myrmeleontidae). J Ethol 36:199-203

Badano D, Pantaleoni RA (2014) The larvae of European Myrmeleontidae (Neuroptera). Zootaxa 3762:1-71
Barkae ED, Scharf I, Ovadia O (2017) Differential effects of variance in prey arrival on foraging success and growth rate of two pit-building antlion species. J Zool 303:254-260

Cain ML (1987) Prey capture method and diel movement of Brachynemurus (Neuroptera: Myrmeleontidae) antlion larvae in south Central Florida. Flo Entomol 70:397-400

Corcoran AJ, Barber JR, Conner WE (2009) Tiger moth jams bat sonar. Science 325:325-327

Czechowski W, Godzińska EJ, Kozłowski MW (2002) Rescue behavior shown by workers of Formica sanguinea Latr., $F$. fusca L. and F. cinerea (Hymenoptera: Formicidae) in response to their nestmates caught by an ant lion larva. Ann Zool 52:423-431

Czechowski W, Radchenko A, Czechowska W, Vepsäläinen K (2012) The ants (Hymenoptera: Formicidae) of Poland with reference to the myrmecofauna of Europe. Natura Optima Dux Foundation, Warszawa

Devetak D, Mencinger-Vračko B, Devetak M, Marhl M, Špernjak A (2007) Sand as a medium for transmission of vibratory signals of prey in antlions Euroleon nostras (Neuroptera: Myrmeleontidae). Physiol Entomol 32:268-274

Eisner T, Baldwin IT, Conner J (1993) Circumvention of prey defense by a predator: ant lion vs. ant. PNAS 90:6716-6720

Fertin A, Casas J (2007) Orientation towards prey in antlions: efficient use of wave propagation in sand. J Exp Biol 210: 3337-3343

Frank ET, Schmitt T, Hovestadt T, Mitesser O, Stiegler J, Linsenmair KE (2017) Saving the injured: rescue behavior in the termite-hunting ant Megaponera analis. Sci Adv 3: e1602187

Gotelli NJ (1996) Ant community structure: effects of predatory ant lions. Ecology 77:630-638

Griffiths D (1980) The feeding biology of the ant-lion larvae: prey capture, handling and utilisation. J Anim Ecol 49:99-125

Heinrich B, Heinrich MJE (1984) The pit-trapping foraging strategy of the ant lion, Myrmeleon immaculatus DeGeer (Neuroptera: Myrmeleontidae). Behav Ecol Sociobiol 14: $151-160$

Hollis KL (2017) Ants and antlions: the impact of ecology, coevolution and learning on an insect predator-prey relationship. Behav Proc 139:4-11

Hollis KL, Nowbahari E (2013) A comparative analysis of precision rescue behaviour in sand-dwelling ants. Anim Behav 85: $537-544$

Hollis KL, Harrsch FA, Nowbahari E (2015) Ants vs. antlions: an insect model for studying the role of learned and hard-wired behaviour in coevolution. Learn Motiv 50:68-82

Hollis KL, McNew K, Sosa T, Harrsch FA, Nowbahari E (2017) Natural aversive learning in Tetramorium ants reveals ability to form a generalizable memory of predators' pit traps. Behav Proc 139:19-25

Humeau A, Rougé J, Casas J (2015) Optimal range of prey size for antlions. Ecol Entomol 40:776-781

Janzen DH (1980) When is it coevolution? Evolution 34:611-612

Jingu A, Hayashi F (2018) Pitfall vs fence traps in feeding efficiency of antlion larvae. J Ethol 36:265-275

Kuszewska K, Miler K, Filipiak M, Woyciechowski M (2016) Sedentary antlion larvae (Neuroptera: Myrmeleontidae) use vibrational cues to modify their foraging strategies. Anim Cogn 19:1037-1041 
Lucas JR, Brockmann HJ (1981) Predatory interactions between ants and antlions (Hymenoptera: Formicidae and Neuroptera: Myrmeleontidae). J Kan Entomol Soc 54:228-232

Matsuda K, Suzuki H, Nakanishi F, Shio K, Komai K, Nishimura K (1995) Purification and characterization of a paralytic polypeptide from larvae of Myrmeleon bore. Biochem Biophys Res Comm 215:167-171

Matsura T (1986) The feeding ecology of the pit-making ant lion larva, Myrmeleon bore: feeding rate and species composition of prey in a habitat. Ecol Res 1:15-24

Matsura T (1987) An experimental study of the foraging behavior of a pit-building antlion larva, Myrmeleon bore. Res Popul Ecol 29:17-26

Miler K (2016) Moribund ants do not call for help. PLoS One 11: e0151925

Miler K, Kuszewska K (2017) Secretions of mandibular glands are not involved in the elicitation of rescue behaviour in Formica cinerea ants. Ins Soc 64:303

Miler K, Yahya BE, Czarnoleski M (2017a) Different predation efficiencies of trap-building larvae of sympatric antlions and wormlions from the rainforest of Borneo. Ecol Entomol 43: $255-262$

Miler K, Kuszewska K, Woyciechowski M (2017b) Larval antlions with more pronounced behavioural asymmetry show enhanced cognitive skills. Biol Lett 13:20160786

Miler K, Yahya BE, Czarnoleski M (2017c) Pro-social behaviour of ants depends on their ecological niche - rescue actions in species from tropical and temperate regions. Behav Proc 144: $1-4$
Miler K, Symonowicz B, Godzińska EJ (2017d) Increased risk proneness or social withdrawal? The effects of shortened life expectancy on the expression of rescue behavior in workers of the ant Formica cinerea (Hymenoptera: Formicidae). J Insect Behav 30:632-644

Moore TY, Biewener AA (2015) Outrun or outmaneuver: predator-prey interactions as a model system for integrating biomechanical studies in a broader ecological and evolutionary context. Integr Comp Biol 55:1188-1197

Morrison LW (2004) Spatiotemporal variation in antlion (Neuroptera: Myrmeleontidae) density and impacts on ant (Hymenoptera: Formicidae) and generalized arthropod foraging. Ann Entomol Soc Am 97:913-922

Nishiwaki H, Ito K, Shimomura M, Nakashima K, Matsuda K (2007) Insecticidal bacteria isolated from predatory larvae of the antlion species Myrmeleon bore (Neuroptera: Myrmeleontidae). J Invert Path 96:80-88

Perry G, Pianka ER (1997) Animal foraging: past, present and future. TREE 12:360-364

Ruxton GD, Hansell MH (2009) Why are pitfall traps so rare in the natural world? Evol Ecol 23:181-186

Taylor K, Visvader A, Nowbahari E, Hollis KL (2013) Precision rescue behavior in north American ants. Evol Psychol 11: 665-677

Publisher's note Springer Nature remains neutral with regard to jurisdictional claims in published maps and institutional affiliations. 